\title{
Enliven: Clinical Dermatology
}

\section{Cutaneous Sarcoidosis on Black Skin: Epidemiological, Clinical and Therapeutic Aspects in Dermatology, Lomé (Togo)}

\author{
Bayaki Saka $^{1 *}$, Julienne Teclessou ${ }^{2}$, Abla Sefako Akakpo ${ }^{1}$, Lihanimpo Djalogue ${ }^{3}$ Abas Mouhari-Toure ${ }^{3}$, Komi Adjoh $^{4}$, Kous- \\ sake Kombaté2, Kissem Tchangaï-Walla', and Palokinam Pitché1 \\ ${ }^{I}$ Department of dermatology and STI, Sylvanus olympio teaching hospital, University of Lomé, Lome, Togo \\ ${ }^{2}$ Department of dermatology and STI, University hospital campus, University of Lome, Lomé, Togo \\ ${ }^{3}$ Dermatology and STI service, Kara University hospital, Kara University, Kara, Togo \\ ${ }^{4}$ Pneumo-phtisiology Department, Sylvanus olympio teaching hospital, University of Lomé, Lomé, Togo
}

"Corresponding author: Dr. Bayaki Saka, Department of dermatology and IST, Sylvanus olympio teaching hospital, University of Lomé, B.P: 30785, Lome, Togo, E-mail: barthelemysaka@yahoo.fr

Received Date: $07^{\text {th }}$ July 2017

Accepted Date: $31^{\text {st }}$ October 2017

Published Date: $07^{\text {th }}$ November 2017
Citation: Saka B, Teclessou J, Akakpo AS, Mouhari-Toure A, Adjoh K, et al. (2017) Cutaneous Sarcoidosis on Black Skin: Epidemiological, Clinical and Therapeutic Aspects in Dermatology, Lomé (Togo). Enliven: Clin Dermatol 3(2): 003.

Copyright: @ 2017 Dr. Bayaki Saka. This is an Open Access article published and distributed under the terms of the Creative Commons Attribution License, which permits unrestricted use, distribution and reproduction in any medium, provided the original author and source are credited.

\section{Abstract \\ Objective}

The purpose of this study was to describe the epidemiological, clinical and therapeutic aspects as well as outcome of cutaneous sarcoidosis in Lomé (Togo).

\section{Methods}

The study is a retrospective data analysis of cutaneous sarcoidosis cases seen during a 17- year period (2000-2016) at the dermatology departments in Lomé, Togo.

Results

In total, 18 cases of cutaneous sarcoidosis were diagnosed; of them, 14 were females and 4 were males. The mean age of the patients was 50.9 years. Cutaneous manifestations were dominated by papules ( 16 cases) and scars sarcoidosis ( 12 cases). Locations of lesions were mainly the face (13 cases) and neck ( 7 cases). Extra cutaneous lesions were essentially lymph nodes ( 5 cases) and respiratory symptoms (4 cases). Chest X-rays was abnormal in 9 of the 14 patients in whom it had been performed. The pulmonary functional test performed in 3 patients with respiratory involvement showed a restrictive lung syndrome. A tuberculin anergy was found in 2 of the 6 patients in whom tuberculin intradermal test was performed. Patients with isolated cutaneous sarcoidosis were treated with topical corticosteroid ( 8 cases) or hydroxychloroquine (one case). The nine other patients were treated with oral corticosteroids, which were replaced by methotrexate after a corticodependence in 2 cases. We recorded 4 cases of clinical remission $(2$ cases of isolated cutaneous sarcoidosis and 2 cases of skin disease with systemic sarcoidosis). The 2 cases of skin disease with systemic sarcoidosis had recurrence 8 months and 12 months later. The remaining 14 patients were lost to follow-up after an average follow-up period of 4 months.

Conclusion

Our survey shows that the patterns of cutaneous sarcoidosis are similar to that reported from other sub-Saharan African countries with a few distinguishing particularities.

Keywords: Cutaneous sarcoidosis;Black skin; Lomé (Togo) 


\section{Introduction}

Sarcoidosis is a systemic granulomatous disease of unknown etiology with skin manifestations $[1,2]$. Skin manifestations are classified as specific if the lesions have granulomas histologically and as nonspecific if they are not characterized by granulomatous inflammation (mainly erythema nodosum) $[3,4]$. In sub-Saharan Africa, many studies have been conducted on cutaneous sarcoidosis particularities in black skin [5-9], but none have been reported in Togo yet. The aim of this study was to report the epidemiology of cutaneous sarcoidosis and describe the clinical, paraclinic and therapeutic aspects of this disease in dermatology units in Togo.

\section{Methods}

We retrospectively reviewed the medical records of all patients diagnosed with cutaneous sarcoidosis at the dermatology departments of Sylvanus Olympio and Campus teaching hospitals, as well as at the Gbossimé dermatology center in Lomé, within a 17-year period (from January 2000 to December 2016). All cases of cutaneous sarcoidosis included in this study were histologically confirmed. Four of the patients included were initially hospitalized in the pneumology unit of the Sylvanus Olympio teaching Hospital, where a dermatological opinion was requested for skin lesions. Paraclinic investigations (chest X-ray, pulmonary function test, intradermal tuberculin test, blood count, serum calcium, protein electrophoresis, angiotensin converting enzyme assay) were not performed in all patients.

\section{Results}

During the study period, 18 cases of cutaneous sarcoidosis were recorded. The mean age of the patients was 58.9 years, ranging from 24 to 69 years. The sex ratio $(\mathrm{F} / \mathrm{M})$ was 0.3 . The mean length time before consultation was 26.4 months, range from 2 months to 15 years. The time to consultation was greater than one year in 8 patients. General symptoms such as asthenia ( 8 cases), weight loss ( 6 cases), fever (1 case) and arthralgia (one case) were noted in 13 patients, with some patients having several types of general symptoms. The main lesions were represented essentially by papules (16 cases) and scars sarcoidosis (12 cases), and mainly located on the face (13 cases) and the neck ( 7 cases) (Table 1). Extra cutaneous lesions were lymph nodes (3 cases), respiratory involvement ( 2 cases), association of lymph nodes and respiratory involvement (2 cases), joints affections (1 case) and neurological involvement (1 case). Biological abnormalities were anemia (one case), acceleration of sedimentation rate ( 6 cases), angiotensin converting enzyme growth (one case) and hypergammaglobulinemia (one case). Chest X-ray was abnormal in nine of the 14 patients in whom it was performed. These were isolated mediastinal lymphadenopathy (stage I, 2 cases), isolated parenchymal damage (stage 2, 5 cases) coexistence of mediastinal lymphadenopathy and parenchymal damage (stage 3, 2 cases). The pulmonary functional test performed in 3 patients with respiratory symptoms showed a restrictive lung syndrome. A tuberculin anergy was found in 2 of the 6 patients in whom tuberculin intradermal test was performed. Patients with isolated cutaneous sarcoidosis were treated with a topical corticosteroid ( 8 cases) or a hydroxychloroquine (one case). The nine other patients were treated with oral corticosteroids, which were replaced by methotrexate following a corticodependence in two cases. We recorded 4 cases of clinical remission ( 2 cases of isolated cutaneous sarcoidosis and 2 cases of skin disease with systemic sarcoidosis). The 2 cases of skin disease with systemic sarcoidosishad recurrence 8 months and 12 months later. The remaining 14 patients were lost to follow-up after an average follow-up period of 4 months.

Table 1: Elementary lesions of cutaneous sarcoidosis and their location

\begin{tabular}{|l|c|c|}
\hline Cutaneous sarcoidosis & Number $(\mathrm{N})$ & $(\%)$ \\
\hline Elementary lesions & & \\
\hline Papules & 16 & 88.9 \\
\hline Scar sarcoidosis & 12 & 66.7 \\
\hline Placards & 3 & 16.7 \\
\hline Nodules & 1 & 5.6 \\
\hline Location of lesions & & \\
\hline Face & 13 & 72.2 \\
\hline Neck & 7 & 38.9 \\
\hline Scalp & 5 & 27.8 \\
\hline Trunk & 4 & 22.2 \\
\hline Arms & 3 & 16.7 \\
\hline Legs & 1 & 5.6 \\
\hline Total & 18 & 100 \\
\hline
\end{tabular}

\section{Discussion}

Our study conducted in dermatology departments in Lomé, during a 17-year period, report 18 cases of cutaneous sarcoidosis. With the 18 cases recorded in 17 years, our study confirms the extreme rarity of cutaneous sarcoidosis in sub-Saharan Africa. An Ivorian study had identified 24 cases of cutaneous sarcoidosis in 25 years [5] and a Senegalese series had recorded 20 cases in 40 years [6]. Also, a Nigerian series had identified 4 cases in 10 years [7]. We believe that this low frequency of cutaneous sarcoidosis in subSaharan Africa could be explained by the lack of economic and geographical accessibility to health services. In addition, it appears that sarcoidosis is generally believed to be rarer in African blacks, especially along the West African coast [8].

The female predominance which was observed in our study is classically observed in cutaneous sarcoidosis [2,10,11], although Kaloga et al. [5] noted an equal incidence among the two sexes.

The clinical patterns of our data are similar to that reported from other subSaharan African countries such as predominance of papules [5,6], or scars sarcoidosis [7,9], predominant location on cephalic regions [5-7] while extra cutaneous lesions are dominated by pulmonary involvement and lymph nodes $[5,6]$. Compare to theses series where the main cutaneous manifestations reported are only papules $[5,6]$, or scars sarcoidosis $[7,9]$, the particularity of our study is the high frequency of both two types of lesions, papules $(88.9 \%)$ and scars sarcoidosis (66.7\%) on black skin in Togo. In fact, scars sarcoidosis are very rare in Kalogaet al. (one case/25) and Niang et al. ( 2 cases/20) series $[5,6]$, and papules are absents in Olumide et al. and Alabi et al. series [7,9]. 
In our study, half of patients had pulmonary damage on chest X-ray, but only 4 had respiratory symptoms. In Ivory Coast, 13 patients had pulmonary damage on chest X-ray but only 5 had respiratory symptoms [5]. These results emphasize on the necessity of a systematic chest X-ray in case of cutaneous sarcoidosis even in the absence of respiratory symptoms, because the treatment would depend on the other organ involvement and the severity of clinical disease.

Concerning the treatment, on one hand, topical corticosteroids and hydroxychloroquine have been effective in patients with isolated cutaneous disease. On the other hand, oral corticosteroids appear to be ineffective in pulmonary involvement since we have recorded two cases of corticodependence and two cases of recurrence after complete remission. These results suggest that low-cost treatments such as methotrexate, isotretinoin, allopurinol that have been shown to be effective [12] could have been used in our context. In addition, 14 of our 18 patients were lost to follow-up after 4 months. It shows the difficulty of long term monitoring of cutaneous sarcoidosis in poor countries where the cost of health care (paraclinic investigations, drugs) is not negligible.

\section{Conclusion}

Cutaneous sarcoidosis is extremely rare in dermatology in Lomé (Togo). It affected mainly female patients. The papules and scars sarcoidosis on cephalic regions (face, neck, scalp) are the main physical signs. The lung and lymph nodes are most commonly affected. Topical corticosteroids and hydroxychloroquine have been effective in patients with isolated cutaneous disease, but oral corticosteroids appear to be ineffective in cutaneous sarcoidosis with systemic involvement.

\section{Limitations}

Some patients may be admitted directly to other departments (neurology, pneumology, ophthalmology, rheumatology units) according to the predominant symptoms of the disease. Our data are therefore not exhaustive, but the results we have achieved, although weak, illustrate the epidemiologic, clinical, paraclinic and therapeutic aspects of cutaneous sarcoidosis in Lomé.

\section{Declarations}

\section{Ethics Approval and Consent to Participate}

This study was approved by the Department of Dermatology of CHU Sylvanus Olympio, Université de Lomé. We obtained the approval from the participants. The participants gave their consent, after the verbal explanation was delivered by the clinicians of the participating hospitals. The survey was anonymous and confidential.

\section{Consent for Publication}

The Department of Dermatology of CHU Sylvanus Olympio, University of Lomé authorized the publication of this manuscript.

\section{Availability of Data and Materials}

The datasets supporting the conclusions of this article are included within the manuscript and its supporting material.

\section{Authors' Contribution}

Bayaki Saka, Julienne Teclessou, Abla Sefako Akakpo, Komi Adjoh and Lihanimpo Djalogue participated in data collection and wrote the manuscript. Abas Mouhari-Toure, Koussake Kombaté, Kissem TchangaïWalla, Palokinam Pitché: have revised and finalized the manuscript. All the authors had read and approved the final manuscript to be submitted for publication.

\section{Acknowledgements}

We would like to thank DrLandoh; MD; MPH for reviewing and copyediting the manuscript.

\section{Authors Information}

Julienne Teclessou, Abla Sefako Akakpo are medical doctors, dermatologists; Bayaki Saka, Abas Mouhari-Toure, Komi Adjoh, Koussake Kombaté, Lihanimpo Djalogue is Medical Doctor, Kissm Thangai-Walla, and PalokinamPitché are medical doctors and professors in dermatology.

\section{References}

1. Descanps V, Bouscarat F (2016) Cutaneous manifestations of sarcoidosis. Ann Dermatol Venereol143: 39-50.

2. Wanat KA, Rosenbach M (2015) Cutaneous sarcoidosis. Clin Chest Med 36: 685-702.

3. Grosshans E, Belaich S, Verret JL, Beylot C (2002) Cutaneous signs of sarcoidosis. Ann Dermatol Venereol129 : S119-S122.

4. Marchell RM, Judson MA (2010) Cutaneous sarcoidosis. Semin Respir Crit Care Med 31: 442-451.

5. Kaloga M, Gbery IP, Bamba V, Kouassi YI, Ecra EJ, et al. (2015) Epidemiological, clinical and paraclinical aspects of cutaneous sarcoodosis in black Africans. Dermatol Res Prat 2015 : 802824.

6. Niang SO, Dieng MT, Kane A, Diop SN, Ndiaye B (2007) Sarcoidosis in Dakar: 30 case reports. Dakar Med 52 :216-222.

7. Olumide YM, Bandele EO, Elesha SO (1989) Cutaneous sarcoidosis in Nigeria. J Am Acad Dermatol 21: 1222-1224.

8. Jacyk WK (1999) Cutaneous sarcoidosis in black South Africans. Int J Dermatol 38:841-845.

9. Alabi GO, George AO (1989) Cutaneous sarcoidosis and tribal scarifications in West Africa. Int J Dermatol 28: 29-31.

10. Ungprasert P, Wetter DA, Crowson CS, Matteson EL (2016) Epidemiology of cutaneous sarcoidosis, 1976-2013: a populationbased study from Olmsted County, Minnesota. J EurAcad Dermatol Venereol30:1799-1804.

11. Khaled A, Souissi A, Zeglaoui F, Mokhtar I, Ezzine N, et al. (2008) Cutaneous sarcoidosis in Tunisia. G Ital Dermatol Venereol143: 181185.

12. Doherty CB, Rosen T (2008) Evidence-based therapy for cutaneous sarcoidosis. Drugs 68: 1361-1383.

Submit your manuscript at
http://enlivenarchive.org/submit-manuscript.php
New initiative of Enliven Archive
Apart from providing HTML, PDF versions; we also provide
video version and deposit the videos in about 15 freely accessible
social network sites that promote videos which in turn will aid in
rapid circulation of articles published with us.

